\title{
Produção científica em Ciências Biológicas da UFRGS: tendências temáticas no período 2000-2011
}

Dirce Maria Santin

Doutoranda em Comunicação e Informação pela UFRGS e Bibliotecária do Instituto de Ciências Básicas da Saúde - UFRGS.

Samile Andréa de Souza Vanz,

Professora Adjunta do Departamento de Ciências da Informação e do Programa de Pós-Graduação em Comunicação e Informação da UFRGS

Ida Regina Chittó Stumpf

Professora Titular do Departamento de Ciências da Informação e do Programa de Pós-Graduação em Comunicação e Informação da UFRGS.

http://dx.doi.org/10.1590/1981-5344/1915

O estudo apresenta as principais temáticas da pesquisa em Ciências Biológicas da Universidade Federal do Rio Grande do Sul (UFRGS) com base na análise da produção científica publicada no período de 2000 a 2011 e indexada na Web of Science (WoS). Destaca as temáticas evidenciadas nas categorias de assuntos e nas palavraschave dos autores de 5.168 artigos que integram a amostra. A metodologia utilizada é a bibliometria e os resultados apontam para Neurociências, Bioquímica \& Biologia Molecular, Farmacologia \& Farmácia e Genética \& Hereditariedade como as áreas mais produtivas, enquanto Estresse oxidativo; Doença; Memória; Receptor; Hipocampo; Rato; e Resistência se destacam como os principais temas de pesquisa. A produção científica apresentou crescimento significativo no período e as tendências temáticas da área constituem objetos de estudo das disciplinas mais produtivas, embora outros temas se mostrem igualmente significativos. Avalia-se que a UFRGS acompanha o desenvolvimento das Ciências Biológicas no contexto nacional e internacional, realizando pesquisas de amplo interesse na atualidade. 
Palavras-chave: Bibliometria; Produção científica; Análise temática; Universidade Federal do Rio Grande do Sul; Ciências Biológicas.

\section{Scientific output in Biological Sciences at UFRGS: thematic trends during the period 2000-2011}

The study presents the main themes of research in Biological Sciences at UFRGS based on the analysis of the scientific production published in the period 2000-2011 and indexed in the Web of Science (WoS). Point the themes highlighted in the subject categories and the keywords of authors of 5,168 articles included in the sample. The methodology is bibliometrics and the results indicate Neuroscience, Biochemistry \& Molecular Biology, Pharmacology \& Pharmacy and Genetics \& Heredity as the most productive areas, while Oxidative stress, Disease, Memory; Receiver; Hippocampus, Rat, and Resistance stand out as the main research themes. The scientific production grew significantly in the period and the thematic trends of area are objects of study the most productive disciplines, although other themes also prove significant. It is estimated that the UFRGS follows the development of Biological Sciences at the national and international context, performing research of ample interest nowadays.

Keywords: Bibliometrics; Scientific output; Thematic analysis; Universidade Federal do Rio Grande do Sul; Biological Sciences.

Recebido em 13.12.2014 Aceito em 03.09.2015

As Ciências Biológicas constituem uma das áreas mais desenvolvidas da UFRGS em ensino e pesquisa e, por consequência, uma das mais importantes em relação à produção científica institucional. A área apresenta estrutura complexa, composta pelo Instituto de Biociências e pelo Instituto de Ciências Básicas da Saúde (ICBS), os quais reúnem três cursos de graduação, dez programas de pós-graduação com oferta de cursos de mestrado e doutorado, um centro de estudos e quatro órgãos auxiliares, além do aporte de pesquisas do Hospital de Clínicas de Porto Alegre (HCPA) e dos mais de 120 grupos de pesquisa existentes em diversas subáreas. 
A UFRGS ocupa a quinta posição entre as instituições brasileiras mais produtivas na Web of Science (WoS), antecedida pela Universidade de São Paulo (USP), Universidade Estadual de Campinas (UNICAMP), Universidade do Estado de São Paulo (UNESP) e Universidade Federal do Rio de Janeiro (UFRJ) (FUNDAÇÃO DE AMPARO À PESQUISA DO ESTADO DE SÃO PAULO - FAPESP, 2010; LETA, 2012). Nas Ciências Biológicas, a Universidade tem obtido resultados significativos e crescentes, não apenas na pesquisa, mas também nos programas de ensino e extensão. No período de 2000 a 2009, a área foi responsável pela publicação de $28 \%$ dos artigos da UFRGS indexados na WoS (BRAMBILLA, 2011).

No Brasil, as Ciências Biológicas tiveram origem nos estudos descritivos da fauna e da flora realizados por pesquisadores e viajantes estrangeiros nos tempos do Império, de modo que representa a base da própria ciência brasileira. Atualmente, a área constitui-se num dos campos mais consolidados do País, com resultados de forte impacto social, cultural e econômico e com relevância nacional e internacional (SCHWARTZMAN, 2001).

O desenvolvimento da área em nível nacional pode ser avaliado pela representatividade dos grupos de pesquisa e dos programas de pósgraduação, além dos números significativos em relação à produção científica brasileira. Os grupos de pesquisa da área totalizam, segundo o último censo do Conselho Nacional de Desenvolvimento Científico e Tecnológico (CNPq, 2010), 3.108, e correspondem a 11,3\% dos grupos nacionais (27.523). Na pós-graduação, são 194 programas com mestrado e doutorado, correspondendo a $16,5 \%$ dos programas nacionais (1.774), além dos cursos independentes de mestrado acadêmico, profissional e doutorado (COORDENAÇÃO DE APERFEIÇOAMENTO DE PESSOAL DE NÍVEL SUPERIOR - CAPES, 2013). A publicação de artigos completos de circulação nacional na área totalizou 38.552 em 2010, representando 11\% dos artigos científicos brasileiros. Os artigos completos de circulação internacional totalizaram 84.397 no período, representando $25 \%$ do total publicado por pesquisadores brasileiros (CONSELHO NACIONAL DE DESENVOLVIMENTO CIENTÍFICO E TECNOLÓGICO - CNPq, 2010).

Os dados apresentados revelam a importância da produção científica brasileira na área de Ciências Biológicas e sua representatividade no contexto nacional. Na UFRGS, a análise das temáticas de pesquisa justifica-se pela trajetória da área na Universidade e pela importância da produção científica no cenário nacional e internacional. Considera-se, também, que as universidades constituem, no Brasil e no exterior, o principal locus da ciência na atualidade e figuram como as principais produtoras de conhecimento científico nos dois contextos (GODIN; GINGRAS, 2000; GUIMARÃES, 2004).

A ciência praticada nas universidades e nas comunidades científicas em geral estrutura-se em diversas áreas do conhecimento, que se caracterizam por diferentes formas de produzir e comunicar os resultados das pesquisas, de acordo com os campos científicos a que pertencem. Essas diferenças entre as disciplinas resultam em maneiras distintas de fazer pesquisa que se refletem na forma como são comunicados os 
resultados científicos para os diversos públicos da ciência (MEADOWS, 1999).

A produção científica tem papel essencial na avaliação da ciência, pois sustenta a avaliação qualitativa (realizada pelos pares) e quantitativa (realizada com base em indicadores bibliométricos) (CASTRO, 1986). A avaliação da produção científica permite inferir sobre os movimentos de institucionalização e desenvolvimento da pesquisa em campos científicos, períodos e contextos específicos. Além de permitir o entendimento dos processos de produção, difusão e uso do conhecimento, também pode orientar o desenvolvimento e a adaptação de políticas científicas, tecnológicas e de inovação.

A análise temática da produção científica de uma área no contexto de um país ou instituição pode contribuir para ampliar o conhecimento dos campos científicos e traçar perspectivas em relação aos temas de pesquisa a serem explorados no futuro. Acredita-se que as temáticas identificadas em determinados campos científicos podem ser consideradas representações confiáveis da produção científica das áreas, pois são expressas por meio de conceitos e terminologias produzidos e utilizados pela própria comunidade científica (KOBASHI; SANTOS 2006). Como método de estudo, a análise temática também permite a identificação dos assuntos e das práticas valorizadas em cada campo, oportunizando a reflexão sobre os temas de pesquisa mais explorados e sobre as possibilidades de desenvolvimento futuro. Ao refletirem sobre as tendências de pesquisa, os estudos de mapeamento permitem verificar como os campos científicos se constituem e como se movimentam os limites e as divisões internas geradas pelas interfaces com outras áreas (BRAMBILLA; STUMPF, 2008).

A identificação das tendências de pesquisa a partir da análise temática da produção científica e a representação cartográfica desses resultados pode ampliar o conhecimento dos pesquisadores e interessados em determinado campo científico no que se refere às características próprias de cada área. Adicionalmente, a análise temática pode refletir os aspectos interdisciplinares da pesquisa, cuja importância é indiscutivelmente crescente na contemporaneidade (KOBASHI, SANTOS, 2006).

Nessa perspectiva, esta pesquisa tem como objetivo identificar as principais temáticas da produção científica em Ciências Biológicas da UFRGS a partir da análise de 5.168 artigos da área publicados no período de 2000 a 2011 e indexados na WoS. Ao analisar as subáreas mais produtivas e relacioná-las com os principais temas de pesquisa evidenciados nas palavras-chave dos artigos, o estudo pretende contribuir para o conhecimento das tendências temáticas da pesquisa da área na UFRGS e oportunizar a análise dos temas que podem ser estimulados em relação à produção científica institucional. 


\section{Procedimentos metodológicos}

O trabalho caracteriza-se como um estudo exploratório, de abordagem quantitativa. Constitui-se num estudo bibliométrico de nível médio de agregação, pois analisa a produção científica de uma instituição, com enfoque numa área do conhecimento (GLÄNZEL, 2003).

A principal fonte de coleta de dados foi o Science Citation Index (SCI) da WoS. A amostra é composta por 5.168 artigos de autores vinculados à UFRGS publicados no período de 2000 a 2011 e indexados em 33 categorias das 75 categorias de assunto da WoS integrantes da disciplina Life Science \& Biomedicine. As categorias contempladas são: Anatomia \& Morfologia; Andrologia; Biodiversidade \& Conservação; Biofísica; Biologia; Biologia Celular; Biologia do Desenvolvimento; Biologia Evolutiva; Biologia Marinha \& de Água Doce; Biologia Matemática \& Computacional; Biologia Reprodutiva; Bioquímica \& Biologia Molecular; Biotecnologia \& Microbiologia Aplicada; Ciências Ambientais; Ciências das Plantas; Doenças Infecciosas; Ecologia; Endocrinologia \& Metabolismo; Entomologia; Farmacologia \& Farmácia; Fisiologia; Genética \& Hereditariedade; Imunologia; Métodos de Pesquisa Bioquímica; Micologia; Microbiologia; Neurociências; Ornitologia; Parasitologia; Patologia; Toxicologia; Virologia; e Zoologia. A seleção das categorias considerou a estrutura da grande área Ciências Biológicas na Tabela de Áreas do Conhecimento do CNPq (2013) e a configuração atual da área na Universidade.

A coleta de dados foi realizada em abril de 2013 a partir do campo Advanced Search da WoS, utilizando a estratégia de busca por endereço da instituição $(A D)$, limitada às categorias de assunto contempladas pela pesquisa (WC), ao período de 2000 a 2011 (PY), ao tipo de documento artigo e ao índice SCI. Os resultados foram exportados da base no formato completo, utilizando a opção Save to Plain Text, em grupos de 500, conforme número máximo permitido para exportação pela WoS, e reunidos em arquivo único.

Os dados foram organizados e analisados com os softwares BibExcel, Microsoft Excel e VOSviewer. A análise das principais temáticas da produção científica ocorreu com base na classificação dos periódicos e, por consequência, dos artigos por eles publicados, nas categorias de assunto da WoS (WoS Categories). A identificação dos principais temas, por sua vez, ocorreu com base nas palavras-chave atribuídas pelos autores às publicações (Author Keywords). As palavras-chave apresentadas nos resultados deste estudo foram traduzidas para português com o uso do Descritores em Ciências da Saúde (DeCS) ${ }^{1}$, a fim de facilitar a compreensão das temáticas em destaque.

Os objetos de análise desta pesquisa são as categorias de assunto da WoS e as palavras-chave dos artigos que compõem a amostra. A metodologia consiste na identificação das categorias de assunto que

\footnotetext{
${ }^{1}$ Vocabulário estruturado trilíngue criado pela Bireme - Centro Latino-Americano e do Caribe de Informação em Ciências da Saúde - com base no MeSH - Medical Subject Headings para uso na indexação e recuperação da informação nas áreas da saúde e correlatas.
} 
reúnem o maior número de artigos, considerando-as as áreas mais produtivas, e no levantamento das palavras-chave atribuídas pelos autores aos artigos analisados, a fim de identificar os temas mais frequentes na produção científica. Entre os 5.168 artigos analisados, 753 $(14,6 \%)$ não contavam com palavras-chave no campo Author Keywords, de modo que suas temáticas não se refletem nos resultados desta pesquisa. Apesar da limitação, optou-se pela análise dos termos registrados neste campo por compreender que as palavras-chave atribuídas aos artigos pelos autores representam adequadamente conceitos e terminologias utilizados pela própria comunidade científica (KOBASHI; SANTOS, 2006).

Do conjunto de palavras-chave identificadas como as de maior ocorrência na produção científica foram excluídos os termos Rio Grande, Sul, Brazil, South America e Southern Brazil por compreender que não representam as temáticas dos artigos. Além disso, o termo Diabetes, que apareceu nas variações Diabete (35 artigos) e Diabetes (24 artigos), teve o número de ocorrências reunidas numa única forma, somando 59 artigos.

Em relação à distribuição dos artigos por categoria de assunto da WoS, adverte-se que o mesmo artigo pode ser classificado em diferentes categorias, de modo que o somatório da ocorrência dos mesmos não corresponde ao número de artigos presentes no conjunto de dados. Destaca-se, também, que a classificação apresentada nos resultados restringe-se às áreas do conhecimento contempladas pela pesquisa, de modo que outras categorias em que os artigos são classificados na fonte de dados não foram mencionadas.

\section{Resultados}

A produção científica em Ciências Biológicas da UFRGS publicada no período de 2000 a 2011 é composta por 5.168 artigos, cuja distribuição por ano de publicação é apresentada no Gráfico 1, acompanhada da taxa de crescimento anual.

Gráfico 1 - Número de artigos publicados em Ciências Biológicas da UFRGSno período 2000 a 2011 e taxa de crescimento anual

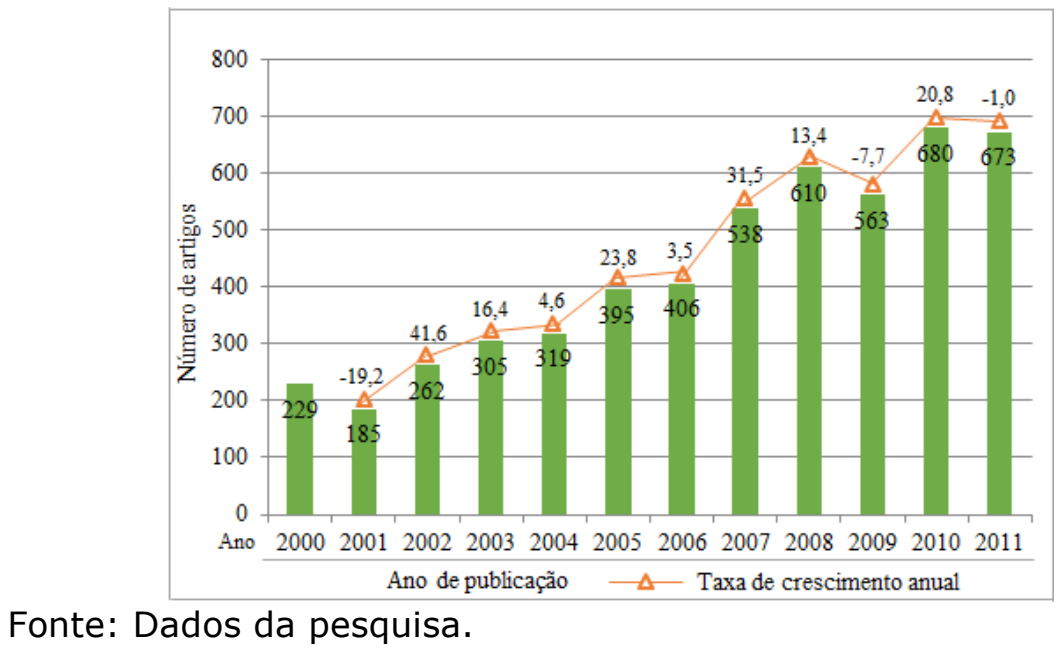

Perspectivas em Ciência da Informação, v.20, n.3, p.3-21, jul./set. 2015 
Observa-se que a produção de artigos é menor nos dois primeiros anos, sendo acompanhada de taxa de crescimento negativa em 2001. Nos anos seguintes, a UFRGS apresentou crescimento constante e significativo na produção de artigos na área, voltando a apresentar queda apenas num período mais recente, correspondente aos anos 2009 e 2011. A variação anual positiva, por outro lado, destaca-se nos anos 2002, 2005, 2007 e 2010.

A ocorrência de taxas de crescimento negativas não compromete o crescimento na produção de artigos da área no período analisado, uma vez que a média de crescimento no período foi de $11,6 \%$. Os resultados acompanham o crescimento da produção científica da Universidade nas diversas áreas, que superou a taxa de $10 \%$ no período de 2002 a 2006 (FAPESP, 2010) e atingiu 12,69 no período de 2000 a 2009 (BRAMBILLA, 2011). Estes dados conferem à UFRGS a quinta posição entre as instituições brasileiras mais produtivas na WoS (FAPESP, 2010; VANZ; STUMPF, 2012; LETA, 2012) e reafirmam a importância da produção científica em Ciências Biológicas no contexto institucional.

Em relação às áreas mais produtivas segundo as categorias de assunto da WoS, foram identificadas as categorias que reúnem o maior número de artigos, as quais foram consideradas as áreas mais produtivas nas Ciências Biológicas da UFRGS no período coberto pela pesquisa. A distribuição dos artigos por categoria de assunto e a porcentagem correspondente são apresentadas na Tabela 1 , seguida da análise das categorias em destaque realizada com base na literatura e na situação atual das áreas na Universidade.

Tabela 1 - Distribuição dos artigos publicados em Ciências Biológicas da UFRGS no período 2000 a 2011 por categoria de assunto da WoS

\begin{tabular}{l|c|c}
\hline \multicolumn{1}{c|}{ Categorias de assunto WoS } & $\mathbf{N}^{\mathbf{0}}$ de artigos & Porcentagem $(\boldsymbol{\%})$ \\
\hline \hline Neurociências & 1.060 & 20,5 \\
\hline Bioquímica \& Biologia Molecular & 769 & 14,9 \\
\hline Farmacologia \& Farmácia & 669 & 9,2 \\
\hline Genética \& Hereditariedade & 475 & 7,8 \\
\hline Ciências das Plantas & 403 & 7,6 \\
\hline Endocrinologia \& Metabolismo & 391 & 6,4 \\
\hline Zoologia & 333 & 5,8 \\
\hline Microbiologia & 302 & 5,7 \\
\hline Biotecnologia \& Microbiologia Aplicada & 296 & 5,5 \\
\hline Biologia & 282 & 5,1 \\
\hline Toxicologia & 265 & 4,3 \\
\hline Biologia Celular & 220 & 3,0 \\
\hline Imunologia & 153 & 2,8 \\
\hline Métodos de Pesquisa Bioquímica & 144 & 2,8 \\
\hline Doenças Infecciosas & 143 & 2,4 \\
\hline Parasitologia & 122 & 2,1 \\
\hline Entomologia & 110 & \\
\hline
\end{tabular}




\begin{tabular}{l|c|c}
\hline Biofísica & 106 & 2,1 \\
\hline Ecologia & 103 & 2,0 \\
\hline Biologia Evolutiva & 98 & 1,9 \\
\hline Fisiologia & 98 & 1,9 \\
\hline Biologia do Desenvolvimento & 93 & 1,8 \\
\hline Biologia Reprodutiva & 93 & 1,7 \\
\hline Micologia & 87 & 1,6 \\
\hline Biologia Marinha \& de Água Doce & 83 & 1,5 \\
\hline Ciências Ambientais & 76 & 1,1 \\
\hline Biodiversidade \& Conservação & 58 & 1,1 \\
\hline Patologia & 58 & 0,4 \\
\hline Biologia Matemática \& Computacional & 23 & 0,4 \\
\hline Virologia & 21 & 0,4 \\
\hline Anatomia \& Morfologia & 20 & 0,3 \\
\hline Ornitologia & 18 & 0,0 \\
\hline Andrologia & 1 & \\
\hline
\end{tabular}

Fonte: Dados da pesquisa.

* Porcentagem calculada sobre o número total de artigos: 5.168 .

Observa-se que Neurociências é a área mais produtiva, sendo responsável por mais de $20 \%$ da produção científica das Ciências Biológicas da UFRGS. Em sequência, destacam-se as áreas de Bioquímica \& Biologia Molecular (14,9\%); Farmacologia \& Farmácia (12,9\%); Genética \& Hereditariedade $(9,8 \%)$, Ciência das Plantas $(7,8 \%)$; e Endocrinologia \& Metabolismo (7,6\%). Outras áreas que agruparam um número considerável de artigos foram: Zoologia (6,4\%); Microbiologia $(5,8 \%)$; Biotecnologia \& Microbiologia Aplicada; Biologia (5,5\%); Toxicologia (5,1\%); e Biologia Celular (4,3\%). As demais áreas, por sua vez, demonstram situações bastante diferentes em relação ao número de artigos, reunindo $33,1 \%$ dos artigos. As áreas que apresentam a menor quantidade de artigos indexados na WoS são Biologia Matemática \& Computacional; Virologia; Anatomia \& Morfologia, ambas com 4,0\% dos artigos; além de Ornitologia $(0,3 \%)$ e Andrologia $(0,0 \%)$.

O Gráfico 2 apresenta o mapeamento da produção científica das 12 áreas mais produtivas no período de 2000 a 2011, considerando o número de artigos publicados. 
Gráfico 2 - 12 principais áreas da produção científica em Ciências Biológicas da UFRGS e número de artigos publicados no período 2000 a 2011

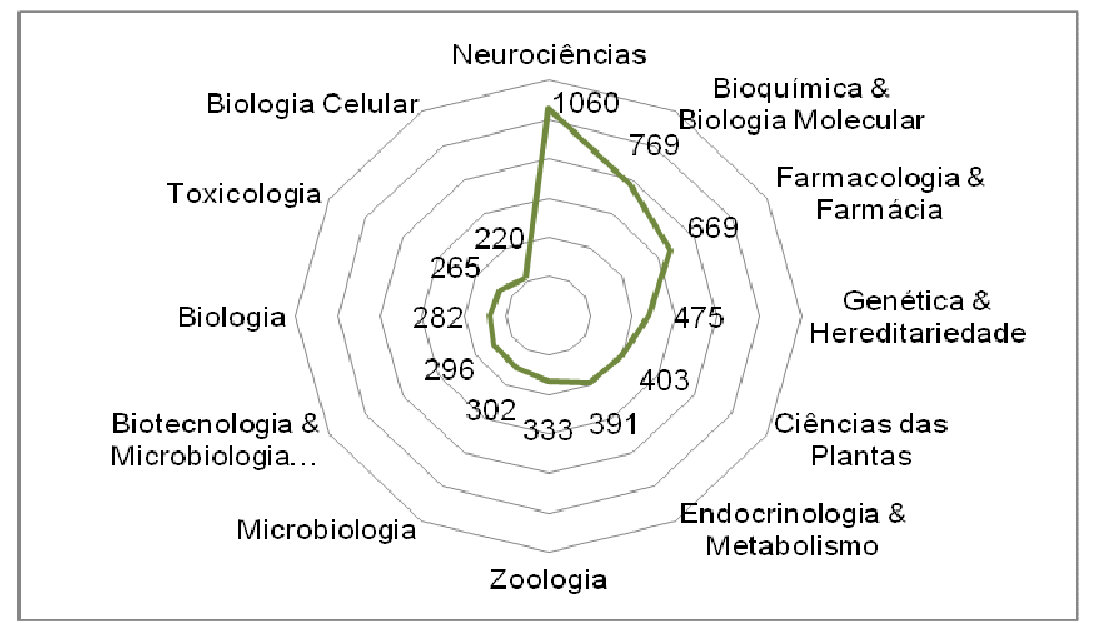

Fonte: Dados da pesquisa.

O gráfico evidencia a alta produtividade da área de Neurociências, considerando o número de artigos e sua distância em relação ao centro do radar. Embora este estudo não pretenda fazer comparações entre o comportamento de publicação das diversas áreas, por reconhecer que cada área tem suas peculiaridades, mesmo quando analisadas dentro de uma grande área (VELHO, 2008), é possível identificar as áreas mais produtivas e relacioná-las com evidências da literatura e com a conjuntura atual na UFRGS.

Nessa perspectiva, considera-se que a alta produtividade de artigos em Neurociências da UFRGS decorre não apenas de sua reconhecida importância no contexto institucional, mas também de sua forte expansão no cenário científico nacional e internacional. A área, que foi eleita como prioritária pelo governo dos Estados Unidos na década de 1990, protagonizou importantes avanços que a colocaram no centro das preocupações da comunidade científica internacional no início do século XXI (VENTURA, 2010). Além disso, é preciso considerar a amplitude das Neurociências e sua estrutura na Universidade, que congrega pesquisadores das áreas de Anatomia, Bioquímica, Fisiologia, Farmacologia, entre outras. Nesse contexto, destacam-se as atividades de diversos grupos de pesquisa e de dois programas de pós-graduação: Programa de Pós-graduação em Ciências Biológicas: Neurociências e Programa de Pós-graduação em Ciências Biológicas: Bioquímica.

Ainda em relação às Neurociências, os resultados obtidos confirmam a ampla atividade da área no período de 2000 a 2009 no que diz respeito à colaboração entre autores e instituições e ainda, ao alto impacto, representado pelas citações recebidas (SANTIN; BRAMBILLA; STUMPF, 2013).

Outra área que apresentou alta produtividade foi Bioquímica \& Biologia Molecular. A área caracteriza-se pela trajetória histórica e pela expansão registrada nas últimas décadas, que resultou em intensos 
impactos conceituais e metodológicos que também incidiram em áreas adjacentes, como Biofísica, Farmacologia, Imunologia, entre outras (PRADO, 1979; MENEGHINI; FONSECA, 1990). Na UFRGS, a trajetória da área foi marcada pelo trabalho de precursores como Tuiskon Dick e Casemiro Victório Tondo, seguidos de pesquisadores que fizeram dela a área mais produtiva em relação à produção científica institucional. Atualmente, a pesquisa em Bioquímica \& Biologia Molecular integra diversos departamentos e grupos de pesquisa, além de dois programas de pós-graduação com excelente avaliação na Capes: Programa de Pósgraduação em Biologia Celular e Molecular (Conceito 6), ligado ao Instituto de Biociências; e Programa de Pós-graduação em Bioquímica (Conceito 7), ligado ao ICBS.

Os resultados observados em relação às áreas de Farmacologia \& Farmácia e Genética \& Hereditariedade também podem ser analisados em relação às características próprias das áreas e seu desenvolvimento no País. As áreas de Farmacologia e Farmácia são marcadas pela tradição dos naturalistas e botânicos desde o século XIX, mas seu desenvolvimento no País ocorreu, sobretudo, a partir da segunda metade do século XX pela associação com áreas correlatas, como Medicina, Bioquímica, Fisiologia e Endocrinologia (VALLE, 1979). A pesquisa em Genética, por sua vez, tem raízes na área agrícola brasileira, onde é empregada sistematicamente desde a década de 1930. A área desenvolveu-se progressivamente e suas pesquisas nos campos da genética das populações, genética médica e citogenética têm gerado resultados de alcance internacional (SCHWARTZMAN, 2001). Em relação à conjuntura atual das áreas na Universidade, observa-se que Farmacologia \& Farmácia constituem enfoques diferentes e complementares, marcados pela pesquisa básica e pela pesquisa clínica. Nesse sentido, destaca-se que os resultados da área também recebem contribuições de pesquisadores vinculados à Faculdade de Farmácia, além daqueles vinculados aos institutos que compõem o contexto desta pesquisa. A alta produtividade da Genética \& Hereditariedade, por sua vez, justifica-se pela trajetória histórica da área na Universidade e por sua estrutura atual, que se caracteriza pela existência de diversos grupos de pesquisa e do Programa de Pósgraduação em Genética. Outro fator propulsor é a parceria mantida entre o Instituto de Biociências da UFRGS, o HCPA e o Instituto Nacional de Genética Médica e Populacional (INaGeMP), que desenvolve pesquisa, prevenção, diagnóstico e tratamento de doenças com fortes componentes genéticos em sua etiologia; forma recursos humanos em Genética; e promove a divulgação científica e a educação das comunidades afetadas.

Além da análise das áreas mais produtivas em Ciências Biológicas da UFRGS, o estudo identificou as principais temáticas da produção científica com base nas palavras-chave atribuídas pelos autores aos artigos, gerando uma listagem de 10.133 termos. A partir desta listagem, verificou-se a frequência relativa das palavras-chave em relação ao conjunto de dados e optou-se pela determinação do ponto de corte na frequência de 0,4\%, correspondente a 20 ocorrências do termo nas palavras-chave dos artigos integrantes da amostra. Obteve-se, assim, 
uma nova listagem de termos, contendo 81 palavras-chave, as quais são apresentadas na Tabela 3, acompanhadas do número de ocorrências e da porcentagem em relação ao conjunto de dados analisados.

Tabela 2 - Principais temas identificados nos artigos em Ciências Biológicas da UFRGS publicados no período 2000 a 2011

\begin{tabular}{|c|c|c|c|c|c|c|c|}
\hline & Palavras-chave & $\mathbf{N}^{\mathbf{o}}$ & $\%$ & & Palavras-chave & $\mathbf{N}^{\mathbf{o}}$ & $\%$ \\
\hline 1 & Estresse oxidativo & 246 & 4,8 & 42 & Ansiedade & 34 & 0,7 \\
\hline 2 & Doença & 168 & 3,3 & 43 & Acetilcolinesterase & 34 & 0,7 \\
\hline 3 & Memória & 156 & 3,0 & 44 & Diagnóstico & 33 & 0,6 \\
\hline 4 & Receptor & 149 & 2,9 & 45 & Esquiva inibitória & 33 & 0,6 \\
\hline 5 & Hipocampo & 137 & 2,6 & 46 & Conservação & 31 & 0,6 \\
\hline 6 & Rato & 130 & 2,5 & 47 & Guanosina & 31 & 0,6 \\
\hline 7 & Resistência & 100 & 1,9 & 48 & $\begin{array}{l}\text { Fator Neurotrófico Derivado do } \\
\text { Encéfalo }\end{array}$ & 30 & 0,6 \\
\hline 8 & Tipo 1 & 92 & 1,8 & 49 & Catalase & 30 & 0,6 \\
\hline 9 & Classificação & 92 & 1,8 & 50 & $\begin{array}{l}\text { Doença da Urina de Xarope de } \\
\text { Bordo }\end{array}$ & 29 & 0,6 \\
\hline 10 & Ensaio & 90 & 1,8 & 51 & Hipertensão & 28 & 0,5 \\
\hline 11 & Polimorfismo & 89 & 1,7 & 52 & Esquizofrenia & 28 & 0,5 \\
\hline 12 & Adenosina & 82 & 1,6 & 53 & Convulsões & 28 & 0,5 \\
\hline 13 & Estresse & 81 & 1,6 & 54 & Citoesqueleto & 27 & 0,5 \\
\hline 14 & Nucleotidase & 76 & 1,5 & 55 & $\begin{array}{l}\text { Proteína Glial Fibrilar } \\
\text { Ácida (GFAP) }\end{array}$ & 27 & 0,5 \\
\hline 15 & Encéfalo & 67 & 1,3 & 56 & Protease & 26 & 0,5 \\
\hline 16 & Comportamento & 59 & 1,1 & 57 & Saccharomyces Cerevisiae & 26 & 0,5 \\
\hline 17 & Diabetes & 59 & 1,1 & 58 & Spray & 26 & 0,5 \\
\hline 18 & Desenvolvimento & 53 & 1,0 & 59 & Estriado & 26 & 0,5 \\
\hline 19 & Glutamato & 52 & 1,0 & 60 & Bacillus & 25 & 0,5 \\
\hline 20 & Morfologia & 52 & 1,0 & 61 & Cafeína & 25 & 0,5 \\
\hline 21 & Captação de glutamato & 48 & 0,9 & 62 & Excitotoxicidade & 25 & 0,5 \\
\hline 22 & Peroxidação de lipídeos & 47 & 0,9 & 63 & Glutationa & 24 & 0,5 \\
\hline 23 & NTPDase & 47 & 0,9 & 64 & Microssatélites & 24 & 0,5 \\
\hline 24 & Astrócitos & 46 & 0,9 & 65 & Óxido nítrico & 24 & 0,5 \\
\hline 25 & Depressão & 45 & 0,9 & 66 & Espécies de oxigênio reativas & 24 & 0,5 \\
\hline 26 & Ecto-5-nucleotidase & 44 & 0,8 & 67 & Retinol & 24 & 0,5 \\
\hline 27 & Neuroproteção & 44 & 0,8 & 68 & Peixe-zebra & 24 & 0,5 \\
\hline 28 & Transtorno bipolar & 43 & 0,8 & 69 & Mania & 23 & 0,4 \\
\hline 29 & Reação em cadeia da polimerase & 43 & 0,8 & 70 & Bacteriocinas & 22 & 0,4 \\
\hline 30 & Antioxidante & 42 & 0,8 & 71 & Carrapato-de-boi & 22 & 0,4 \\
\hline 31 & Córtex cerebral & 42 & 0,8 & 72 & Expressão gênica & 22 & 0,4 \\
\hline 32 & Validação & 42 & 0,8 & 73 & Soja & 22 & 0,4 \\
\hline 33 & Fosforilação & 40 & 0,8 & 74 & Imunoistoquímica & 22 & 0,4 \\
\hline 34 & Proteína S100B & 39 & 0,7 & 75 & Criança & 21 & 0,4 \\
\hline 35 & Homocisteína & 38 & 0,7 & 76 & Metarhizium Anisopliae & 21 & 0,4 \\
\hline 36 & Filogenia & 38 & 0,7 & 77 & Serotonina & 21 & 0,4 \\
\hline 37 & Creatina quinase & 37 & 0,7 & 78 & Superóxido dismutase & 21 & 0,4 \\
\hline 38 & Radicais livres & 37 & 0,7 & 79 & Carrapato & 21 & 0,4 \\
\hline 39 & Genotoxicidade & 37 & 0,7 & 80 & Ectonucleotidases & 20 & 0,4 \\
\hline 40 & Metabolismo energético & 36 & 0,7 & 81 & Novas espécies & 20 & 0,4 \\
\hline 41 & Diabetes Mellitus & 35 & 0,7 & & & & \\
\hline
\end{tabular}

Fonte: Dados da pesquisa. 
Verifica-se uma grande quantidade de temas de pesquisa incidentes em 20 ou mais artigos, os quais correspondem a diversas subáreas das Ciências Biológicas da UFRGS. Nas primeiras 10 posições, destacam-se os seguintes temas: Estresse oxidativo, incidente em 246 artigos (4,8\%); Doença, em 168 artigos (3,3\%); Memória, em 156 artigos (3,0\%); Receptor, em 149 artigos (2,9\%); Hipocampo, em 137 artigos (2,6\%); Rato, em 130 artigos (2,5\%); Resistência, em 100 artigos (1,9\%); Tipo 1, em 92 artigos (1,8\%); Classificação, também em 92 artigos (1,8\%); e Ensaio, em 90 artigos (1,8\%). Observa-se que o intervalo de ocorrências entre o primeiro e o décimo termo é significativo, o que destaca ainda mais a importância do termo Estresse oxidativo na produção científica da instituição.

A forte incidência do termo Estresse Oxidativo nas palavras-chave dos artigos em Ciências Biológicas da UFRGS pode ser associada à importância assumida pelo tema na atualidade em nível global. Ohniwa, Hibino e Takeyasu (2010) destacaram o crescimento das publicações sobre o assunto no período de 1997 a 2001 na PubMed, a partir da análise dos termos do Medical Subject Headings (MeSH) atribuídos aos artigos indexados na base de dados. Hern II e colaboradores (2007) identificaram o tema como um dos principais tópicos de pesquisa do National Institutes of Health dos Estados Unidos no ano de 2007, com base na análise dos subsídios concedidos pelo organismo às pesquisas realizadas no país. Outro aspecto relevante em relação ao tema é sua interdisciplinaridade, pois compreende estudos de diversas subáreas sobre as perturbações no equilíbrio celular que podem ocasionar diferentes lesões nos organismos vivos (DeCS, 2013).

O grupo das dez principais palavras-chave pode ser caracterizado pela forte presença de temáticas relacionadas às Neurociências, acompanhando a alta produtividade da área verificada na análise das categorias de assunto. Entretanto, considerando a interdisciplinaridade de alguns termos, também é possível identificar temas de pesquisa das áreas de Bioquímica \& Biologia Molecular, Fisiologia, Endocrinologia \& Metabolismo, Patologia e Ciências das Plantas. O termo Rato (2,5\%), embora de caráter geral, indica a importância do principal modelo animal utilizado nos experimentos, ainda que outros modelos também recebam destaque na tabela. Os termos Doença (3,3\%), e Ensaio $(1,8 \%)$ demonstram o alcance da produção científica em Ciências Biológicas da UFRGS na pesquisa clínica (diagnóstico/tratamento de doenças e desenvolvimento de novos medicamentos), onde os ensaios são considerados importantes meios de registro e comunicação dos resultados das pesquisas (BRASIL. Ministério da Saúde, 2011).

Ampliando a análise para as 10 posições seguintes, que compreendem o intervalo de 52 a 89 ocorrências dos termos, observa-se uma expansão no leque de temáticas e áreas de estudo, embora algumas áreas se mantenham em destaque, como é o caso de Neurociências e Bioquímica \& Biologia Molecular. Destaca-se neste grupo o termo Diabetes, fortemente relacionado ao termo Tipo 1 existente no primeiro grupo e que ressurge com a palavra-chave Diabetes Mellitus na $41^{a}$ 
posição. Observa-se que a soma dos três termos resulta em 186 artigos, os quais representam $3,6 \%$ do total da amostra, embora os termos possam coocorrer em alguns artigos. De qualquer forma, os dados permitem inferir a importância desta temática de pesquisa na UFRGS, a qual congrega esforços das áreas de Fisiologia e Endocrinologia \& Metabolismo, entre outras. Neste grupo também merecem destaque os termos Polimorfismo, vinculado especialmente à área de Genética \& Hereditariedade, e o termo Morfologia, cujo maior enfoque ocorre nas áreas de Zoologia e Ciências das Plantas. O termo Desenvolvimento, por sua vez, tem caráter essencialmente amplo, mas pode ser associado às áreas de Genética \& Hereditariedade, Biologia do Desenvolvimento, Fisiologia, Biologia Celular, entre outras.

O próximo grupo pode ser observado a partir do termo Captação de glutamato, que ocupa a $21^{a}$ posição, até o termo Metabolismo energético, que ocupa a posição de número 40. Apesar da amplitude do intervalo e da impossibilidade de especificar a importância de cada termo para cada subárea envolvida, percebe-se a preponderância de termos relacionados às áreas de Bioquímica e Biologia Molecular, Biologia Celular, Neurociências, Fisiologia, Farmacologia \& Farmácia, Endocrinologia \& Metabolismo, Genética \& Hereditariedade, entre outras. Observa-se que neste grupo, assim como em outros pontos da tabela, proteínas e enzimas são temáticas frequentes na pesquisa em Ciências Biológicas da UFRGS, acompanhando tendências internacionais de pesquisa verificadas por autores como Mane e Börner (2004), Ohniwa, Hibino e Takeyasu (2010) e Cantos-Mateos e colaboradores (2012).

O grupo de palavras-chave que compreende as posições de número 42 a 60 relaciona-se fortemente à área de Neurociências, com temos como Ansiedade $(0,7 \%)$, Esquiva inibitória (06\%), Fator Neurotrófico Derivado do Encéfalo (0,6\%), Esquizofrenia $(0,5 \%)$, Convulsões $(0,5 \%)$ e Estriado $(0,5 \%)$, e às áreas de Biotecnologia \& Microbiologia Aplicada, Bioquímica \& Biologia Molecular, Biologia Celular, Genética \& Hereditariedade, entre outras. O termo Conservação $(0,6 \%)$ também pode ser destacado neste grupo, associado especialmente às áreas de Ecologia, Ciências Ambientais e Biodiversidade \& Conservação. Nas áreas Endocrinologia \& Metabolismo e Farmacologia \& Farmácia é possível situar o termo Hipertensão $(0,5 \%)$, embora seu uso ocorra também em outros campos. O termo Saccharomyces Cerevisiae $(0,5 \%)$, por sua vez, refere-se às pesquisas que envolvem o fungo de mesmo nome, também conhecido como levedura do pão ou da cerveja (DeCS, 2013).

O último grupo de termos compreende as palavras-chave registradas nas posições de número 61 a 81 da tabela. Destaca-se a presença do termo Peixe-zebra $(0,5 \%)$, representando um modelo animal utilizado com menor frequência que o rato, mas cuja importância tem se mostrado crescente nas pesquisas nacionais e internacionais, especialmente nas Neurociências e em outras áreas dedicadas ao estudo dos efeitos dos agentes químicos no desenvolvimento (ZORZETTO; GUIMARÃES, 2013). Os termos Carrapato-de-boi $(0,4 \%)$ e Carrapato 
$(0,4 \%)$, por sua vez, demonstram a importância das pesquisas em Zoologia, Parasitologia e Virologia, que também podem ser associadas a outros termos listados na tabela. O termo Soja $(0,4 \%)$, também conhecido como Feijão de Soja, relaciona as pesquisas das áreas de Genética \& Hereditariedade e Ciência das Plantas com as Ciências Agrárias, ratificando a relação existente entre esta grande área e as Ciências Biológicas. Merece destaque, por fim, o termo Novas espécies $(0,4 \%)$, que aparece na última posição da tabela e nos oportuniza destacar outra subárea importante na pesquisa em Ciências Biológicas da UFRGS não mencionada até o momento: a Biologia Evolutiva. A área está intimamente relacionada à Genética \& Hereditariedade e pode ser igualmente associada ao termo Soja, mencionado recentemente.

Algumas temáticas identificadas nesta pesquisa correspondem a tendências temáticas das áreas biomédicas verificadas em estudos anteriores, indicando que a UFRGS desenvolve pesquisas em temas de amplo interesse na atualidade. Além do termo Estresse Oxidativo, destacado anteriormente, Ohniwa, Hibino e Takeyasu (2010) verificaram a forte incidência dos termos Enzimas, Proteínas, Polimorfismo e Ratos nos artigos indexados na PubMed com termos do MeSH para diferentes períodos entre os anos de 1972 a 2006, indicando as tendências da pesquisa global nas Ciências da Vida. Mane e Börner (2004) analisaram as temáticas dos artigos publicados no periódico Proceedings of National Academy of Sciences of the United States of America (PNAS), no período de 1982 a 2001 e identificaram temáticas como Receptor, Rato, Inibição entre os principais tópicos dos artigos, além de temas mais amplos como proteínas, bases moleculares e genoma, os quais podem ser associados a diversas palavras-chave identificadas nesta pesquisa.

A Figura 1 possibilita a visualização dos principais temas da produção científica da área no período de 2000 a 2011, destacando os termos que tiveram pelo menos 20 ocorrências no conjunto de palavraschave dos artigos.

Figura 1 - Mapa dos principais temas dos artigos publicados em Ciências Biológicas da UFRGS 2000-2011

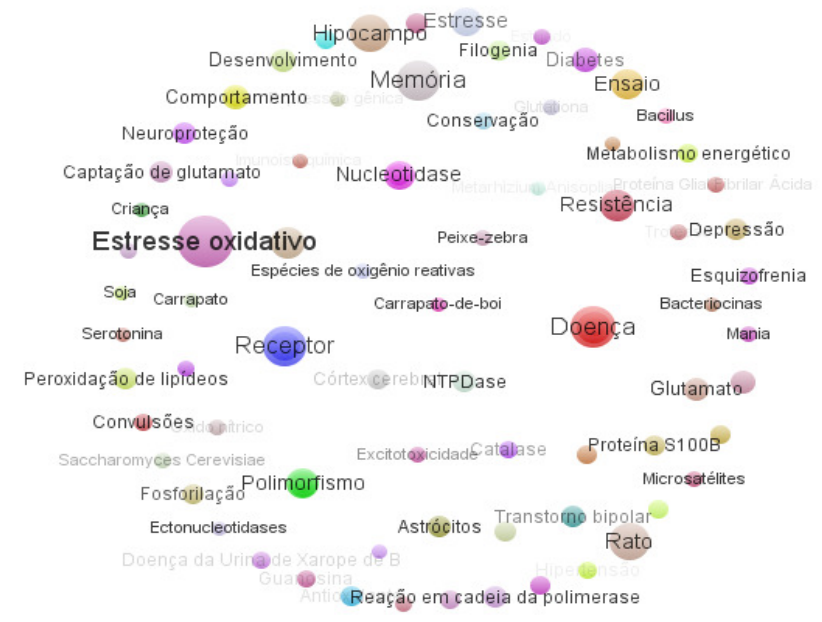

Fonte: Dados da pesquisa. 
A visualização obtida pelo VOSviewer permite que se identifiquem rapidamente as tendências temáticas da produção científica em Ciências Biológicas da UFRGS. Quanto maior a ocorrência dos termos nas palavraschave, maior é o círculo correspondente. Enquanto as dimensões dos círculos revelam a importância das áreas altamente produtivas e o agrupamento por cores demonstra a proximidade entre os principais temas de pesquisa. Observa-se que os temas vinculados aos círculos de maior dimensão referem-se novamente a Estresse oxidativo, Doença, Memória, Receptor, Hipocampo, Rato, Resistência, Ensaio, Polimorfismo, entre outros. Em relação às cores, verifica-se que grande parte dos círculos recebe a cor vermelha e tonalidades variantes, como é o caso do rosa, por exemplo, demonstrando a interdisciplinaridade das temáticas de pesquisa.

A interdisciplinaridade presente na ciência e nas principais temáticas da produção científica da área na UFRGS, associada ao espaço disponível neste trabalho, nos impede de atribuir os termos destacados às diversas subáreas envolvidas. É possível observar, no entanto, a partir das próprias temáticas apresentadas, a ênfase da área na pesquisa básica, que constitui o estudo teórico e experimental dos fenômenos para possível aplicação (BRASIL. Ministério da Saúde, 2011). Sabe-se, entretanto, que a pesquisa básica pode ser orientada em função de áreas mais amplas de interesse geral, aspecto que justifica e qualifica a presença de temas relacionados à pesquisa clínica (áreas da saúde) e à pesquisa aplicada (áreas agrícolas) entre as principais temáticas da produção científica em Ciências Biológicas da UFRGS.

A investigação científica é altamente dinâmica e as tendências temáticas podem variar rapidamente, pois as áreas se modificam e os temas evoluem no decorrer do tempo (MANE; BORNER, 2004). A pesquisa em Ciências Biológicas tem experimentado forte crescimento e diversificação no mundo todo, e estas transformações se refletem na variedade de temáticas identificadas nesta pesquisa, ainda que o estudo esteja restrito à produção científica de uma universidade brasileira.

\section{Considerações finais}

A produção científica em Ciências Biológicas corresponde a cerca de $30 \%$ dos artigos publicados pela UFRGS no período de 2000 a 2011 e indexados na WoS, tendo apresentado crescimento significativo no período, com média $11,6 \%$ ao ano. Os dados reafirmam a importância da produção científica da área no contexto institucional e contribuem para manter a Universidade entre as cinco instituições brasileiras mais produtivas na WoS. No que se refere à produção científica brasileira em Ciências Biológicas, avalia-se que a UFRGS tem registrado participação significativa, acompanhando o crescimento da área no contexto nacional e contribuindo para aumentar sua representatividade no cenário internacional.

A análise das tendências temáticas da produção científica em Ciências Biológicas da UFRGS publicada no período de 2000 a 2011 
revelou a prevalência de áreas e temáticas relacionadas no conjunto de artigos analisados. Enquanto as áreas mais produtivas, segundo a classificação de assuntos da WoS, são Neurociências, Bioquímica \& Biologia Molecular, Farmacologia \& Farmácia, e Genética \& Hereditariedade, os principais temas de pesquisa referem-se a Estresse oxidativo, Doença, Memória, Receptor, Hipocampo, Rato, Resistência, segundo as palavras-chave atribuídas pelos autores aos artigos. É possível avaliar, portanto, que as principais temáticas de pesquisa constituem objetos de estudo das áreas mais produtivas, embora outros temas se mostrem igualmente significativos.

Algumas das tendências temáticas identificadas nesta pesquisa correspondem a importantes temas de pesquisa das áreas biomédicas destacados em estudos anteriores. A situação demonstra que as Ciências Biológicas da UFRGS acompanham o desenvolvimento da área no contexto nacional e internacional, realizando pesquisas de amplo interesse na atualidade. Apesar disso, temas mais específicos também foram observados nas palavras-chave de maior ocorrência nos artigos, indicando enfoques particulares na produção científica.

Em relação às principais temáticas identificadas a partir das palavras-chave atribuídas pelos autores acredita-se que, embora não constituam unidades de controle terminológico, visto que não garantem o uso de vocabulário controlado, representam adequadamente as tendências temáticas da área na Universidade, pois destacam conceitos e termos utilizados pela própria comunidade científica. Ressalta-se, entretanto, que a opção pela normalização dos descritores com base em vocabulário controlado específico ou pela análise das palavras-chave atribuídas pela WoS aos artigos (Keyword plus) poderia destacar outras temáticas da área não identificadas neste estudo, de modo que tais possibilidades podem ser exploradas em futuras pesquisas.

Além das áreas mais produtivas e das tendências temáticas da produção científica da área no contexto institucional, o estudo também revelou os aspectos interdisciplinares da pesquisa nesta área, cuja maior parte dos temas não é objeto exclusivo de uma subárea ou de um campo do saber. Esta característica acompanha tendência comum às diversas áreas do conhecimento na contemporaneidade, que tem se mostrado bastante forte nas ciências naturais e ganha especial destaque quando os diversos campos são reunidos sob a estrutura de uma grande área do conhecimento, como é o caso das Ciências Biológicas no Brasil.

Observa-se, por fim, que, embora restrito à análise temática da produção científica publicada na forma de artigos e indexada na WoS, o estudo contribui para o conhecimento das tendências temáticas da pesquisa em Ciências Biológicas da UFRGS e oportuniza a análise dos temas que podem ser estimulados em relação à produção científica institucional. Adicionalmente, possibilita a reflexão sobre as características próprias desta área, que congrega disciplinas voltadas especialmente à pesquisa básica sobre os fenômenos da vida e os processos vitais. 


\section{Referências}

BRAMBILLA, S. D. S. Produção científica da Universidade Federal do Rio Grande do Sul representada na Web of Science: 2000-2009. 219 f. 2011. Tese (Doutorado em Comunicação e Informação) - Universidade Federal do Rio Grande do Sul. Porto Alegre, 2011. Disponível em: <http://hdl.handle.net/10183/28922>. Acesso em: 20 jul. 2013.

BRAMBILLA, S. D. S.; STUMPF, I. R. C. Interfaces da informação: tendências temáticas da pós-graduação: linhas de pesquisa. Informação \& Sociedade: Estudos, João Pessoa, v. 18, n. 3, p. 105-119, set./dez. 2008. Disponível em: <http://www.ies.ufpb.br/ojs/index.php/ies/article/view/2179/2277>. Acesso em: 21 ago. 2013.

BRASIL. Ministério da Saúde. Fortalecendo a pesquisa clínica no Brasil: a importância de registrar os ensaios clínicos. Revista de Saúde Pública, São Paulo, v. 42, n. 2, p. 436-439, abr. 2011. Disponível em: <http://bvsms.saude.gov.br/bvs/is_digital/is_0211/pdfs/IS31(2)045.pdf> . Acesso em : 26 ago. 2013.

CANTOS-MATEOS, G. et al. Stem cell research: bibliometric analysis of main research áreas through Key Words Plus. Aslib Proceedings, London, v. 64, n. 6, p. 561-590, 2012.

CASTRO, C. M. Ciência e universidade. Rio de Janeiro: Zahar, 1986.

CONSELHO NACIONAL DE DESENVOLVIMENTO CIENTÍFICO E TECNOLÓGICO (CNPq). Tabela de áreas do conhecimento. Brasília, 2013.

Disponível

em:

<http://www.cnpq.br/documents/10157/186158/TabeladeAreasdoConheci mento.pdf>. Acesso em: 23 ago. 2013.

CONSELHO NACIONAL DE DESENVOLVIMENTO CIENTÍFICO E TECNOLÓGICO (CNPq). Diretório de Grupos de Pesquisa no Brasil. Brasília, 2010. Disponível em: <http://dgp.cnpq.br/censos/>. Acesso em: 10 set. 2013.

COORDENAÇÃO DE APERFEIÇOAMENTO DE PESSOAL DE NÍVEL SUPERIOR (CAPES). Relação de cursos recomendados e reconhecidos. Brasília, 2013. Disponível em: <http://www.capes.gov.br/avaliacao/cursosrecomendados-e-reconhecidos>. Acesso em: 10 set. 2013.

DESCRITORES EM CIÊNCIAS DA SAÚDE (DeCS). Saccharomyces cerevisiae. Disponível em: <http://decs.bvs.br/>. Acesso em: 7 out. 2013.

FUNDAÇÃO DE AMPARO À PESQUISA DO ESTADO DE SÃO PAULO (FAPESP). Indicadores de Ciência, Tecnologia e Inovação em São Paulo 2010. São Paulo, 2010. Disponível em: <http://www.fapesp.br/6479>. Acesso em: 20 set. 2013.

GLÄNZEL, W. Bibliometrics as a research field. 2003. Disponível em: <http://nsdl.niscair.res.in/bitstream/123456789/968/1/>. Acesso em: 6 ago. 2013. 
GODIN, B.; GINGRAS, Y. The place of universities of the system of knowledge production. Research Police, Amsterdam, v. 29, n. 2, p. 273278, 2000.

GUIMARÃES, J. A. A pesquisa médica e biomédica no Brasil: comparações com o desempenho científico brasileiro e mundial. Ciência e Saúde Coletiva, Rio de Janeiro, v. 9, n. 2, p. 303-327, abr. /jun. 2004. Disponível em: <http://www.scielo.br/pdf/csc/v9n2/20387.pdf>. Acesso em: 4 set. 2013 .

HERN II, B. W. et al. A topic map of NIH grants 2007. 2010. Disponível em: <http://scimaps.org/maps/map/a_topic_map_of_nih_g_84/>. Acesso em: 9 out. 2013.

KOBASHI, N. Y.; SANTOS, R. N. M. Institucionalização da pesquisa científica no Brasil: cartografia temática e de redes sociais por meio de técnicas bibliométricas. Transinformação, Campinas, v. 18, n. 1, p. 27-36, jan.-abr. 2006. Disponível em: <http://periodicos.puccampinas.edu.br/seer/index.php/transinfo/article/view/680>. Acesso em: 3 set. 2013.

LETA, J. Brazilian growth in the mainstrean science: the role of human resources and national journals. Journal of Scientometrics Research, Mumbai, v. 1, n. 1, set./dez. 2012. Disponível em: <http://www.jscires.org/temp/JSciRes1144-2977039_081610.pdf>.

Acesso em: 10 out. 2013.

MANE, K. K.; BÖRNER, K. Mapping topics and topic bursts in PNAS. Proceedings of National Academy of Sciences of the United States of America - PNAS, Washington, v. 101, supl. 1, p. 5287-5290, abr. 2004.

MEADOWS, A. J. A comunicação científica. Brasília: Briquet de Lemos, 1999.

MENEGHINI, R.; FONSECA, L. Índices alternativos de avaliação da produção científica em Bioquímica no Brasil. Ciência e Cultura, Campinas, v. 42, n. 9, p. 629-645, set. 1990.

OHNIWA, R. L.; HIBINO, H.; TAKEYASU, K. Trends in research foci in life science fields over the last 30 years monitored by emerging topics. Scientometrics, Amsterdam, v. 85, n. 1, p. 111-127, out. 2010.

PRADO, J. L. A bioquímica no Brasil. In: FERRI, M. G.; MOTOYAMA, S. História das ciências no Brasil. São Paulo: EdUSP, 1979. p. 111-150.

SANTIN, D. M.; BRAMBILLA, S. D. S.; STUMPF, I. R. C. Produção científica em Neurociências da UFRGS indexada na Web of Science: 2000-2009. Liinc em Revista, Rio de Janeiro, v. 9, n. 1, p. 66-84, maio 2013. Disponível em: <http://revista.ibict.br/liinc/index.php/liinc/article/viewFile/511/392>. Acesso em: 22 jun. 2013. 
SCHWARTZMAN, S. Um espaço para a ciência: a formação da comunidade científica no Brasil. Brasília: Ministério da Ciência e Tecnologia; Centro de Estudos Estratégicos, 2001.

VALLE, J. R. A farmacologia no Brasil. In: FERRI, M. G.; MOTOYAMA, S. História das ciências no Brasil. São Paulo: EdUSP, 1979. p. 175-189.

VANZ, S. A. S.; STUMPF, I. R. C. Scientific output indicators and scientific collaboration network mapping in Brazil. Collnet Journal, New Delhi, v. 6, p. 1-20, 2012.

VELHO, L. Estudos de cienciometria na América Latina. In: ENCONTRO BRASILEIRO DE BIBLIOMETRIA E CIENTOMETRIA, 1., 2008. Estudos de cienciometria na América Latina [Palestra]. Rio de Janeiro, 2008. Disponível em: <http://www.eventos.bvsalud.org/agendas/ebbc1/public/documents/LEA \%20VELHO-092900.pdf>. Acesso em: 23 mar. 2013.

VENTURA, D. F. Um retrato da área de Neurociência e Comportamento no Brasil. Psicologia: teoria e pesquisa, Brasília, v. 26, n. esp., p. 123-129, 2010.

ZORZETTO, R.; GUIMARÃES, M. Um peixe modelo. Pesquisa FAPESP, São Paulo, n. 209, jul. 2013. Disponível em: <http://revistapesquisa.fapesp.br/2013/07/12/um-peixe-modelo/>. Acesso em: 11 out. 2013. 